\title{
Health literacy beyond knowledge and behaviour: letting the patient be a patient
}

\author{
Sara Rubinelli $\cdot$ Peter J. Schulz $\cdot$ Kent Nakamoto
}

Published online: 30 July 2009

(c) Birkhäuser Verlag, Basel/Switzerland 2009

\section{Introduction}

Health literacy is widely regarded as critical for managing personal health (Nutbeam and Kickbusch 2000; Schloman 2004; Andrus and Roth 2002) and is an important sociopolitical issue in that limited health literacy can result in enormous burdens to healthcare systems (Dubow 2004; DeBuono 2004). Lack of specific skills and knowledge associated with health literacy has been shown to negatively affect people's understanding and use of information provided by health professionals.

Much descriptive research has sought to elucidate the concept of health literacy, its measurement, and the problem of low health literacy. The term "health literacy" was first used by Simonds in the context of school health education. Simonds argued for the importance of students becoming as "literate" in health as they were in other disciplines (Ratzan 2001). This view crystallized an understanding of health literacy as "functional literacy", as exemplified by the American Medical Association report where health literacy is conceived as "the ability to read and comprehend prescription bottles, appointment slips, and the other essential health-related materials" (Ad hoc committee on health literacy for the counsel of scientific affairs. American Medical Association 1999).

This functional approach to health literacy assumes epistemic objectivity; that is, reading skill and comprehension

S. Rubinelli $(\bowtie) \cdot$ P. J. Schulz

Institute of Communication and Health, University of Lugano,

Via Buffi 13, 6904 Lugano (CH), Switzerland

e-mail: sara.rubinelli@lu.unisi.ch

K. Nakamoto

Department of Marketing, Virginia Tech, Blacksburg, VA, USA are objectively measurable. Certainly, deficiencies in reading and numeracy skills represent a major barrier to health education and management (Brown et al. 2003; Schloman 2004; Williams et al. 1995; Parker et al. 2003), and this has given rise to a large body of research on proposing tests for assessing literacy levels and strategies for improving the accessibility of materials such as patient education leaflets and informed-consent documents (Maag 2005). In recent years, however, an expanded view of health literacy has been motivated by evidence of an at best weak link between the ability to read and understand health communication and patients' actual performance. This gap between functional skills and patient practice created the need to extend the definition of health literacy to include factors that can influence health decisions (Ratzan 2001; Kickbusch and Ratzan 2001; Cutilli 2005; Parker 2000; Nutbeam 2000; McCray 2005) as reflected in the WHO definition of health literacy as "the cognitive and social skills which determine the motivation and ability of individuals to gain access to, understand and use information in ways which promote and maintain good health" (World Health Organization 1998).

Some recent definitions of health literacy have expanded the concept to the point where literacy becomes the ability to make sound decisions in all domains; from home and the workplace to the political arena (Kickbusch et al. 2005).

However, with these skill-based enrichments of the concept (especially in health promotion-oriented visions), health literacy has grown broader in extension but impoverished in its intension. Factors that extend the limited definition of functional literacy have been incorporated but, at the same time, have lost focus on the central link between the person's goals and actions, reducing health literacy to a set of skills and taking for granted motivation and the meaning of "good health". 
In this paper, we explore weaknesses of current views of health literacy and then consider specific aspects of the concept that seem to play at its core. We conceptualize health literacy as closely related to an Aristotelian "phronesis", where skills represent only one of its components. The concept of phronesis is well known in medical humanities to characterise the skilful reasoning of the physician during diagnosis and prognosis (Davis 1997; Macnaughton 1998), but it can also serve to highlight crucial aspects of health literacy. We illustrate this using messages posted on an online forum by a group of chronic low back pain patients.

\section{Health literacy and empowerment}

Several current discussions on health literacy hold that its purpose is to enable the individual to use knowledge as an independent agent, thus "empowering" him/her to make choices that preserve, improve or manage health (Abel 2007). This view has enriched the concept of health literacy by including essential dimensions of medical knowledge and a varied set of skills that people need to find, evaluate, negotiate on and apply health information (Wang 2000; Levin-Zamir and Peterburg 2001). Nutbeam (2000), for example, encapsulates these skills as functional, interactive and critical literacy that incorporate psychological, social and environmental factors.

Apart from the difficulty of grasping what some of these skills actually involve (Tones 2002), a serious concern that arises is that, given the skills that being empowered implies, it is no longer clear how the competences that patients need to acquire differ from those of physicians. The literature does not address this issue but attempting to clarify this distinction between literacy and professional expertise leads to a paradox.

If the patient's knowledge and skills (literacy) are not commensurate with those of the doctor, then the skillattainment vision of health literacy leads to the patient as a pale shadow of the physician. Such literacy might empower the patient and make him more independent in the health system, but results in a dangerous independence. Empowerment might lead the patient to overestimate his real competences and to favour deleterious health choices inspired by insufficient expertise. If, on the contrary, the patient's knowledge and skills are "close" to those of the doctor then health literacy is tantamount to making the patient into a health professional, a goal that is unrealistic and unreachable.

We believe that the concept of health literacy should be re-framed in a way that avoids this paradox but at the same time preserves its important value as a key component of individual self-healthcare. To do so, we argue that health literacy must be re-grounded in the individual's existential experience.

\section{The goal of health enhancement}

Consider two examples:

Example 1 Andrew, who works in an institute of preventive medicine, has been asked to design an antismoking campaign. He has all knowledge necessary to design the campaign: numerous medical reports on the risks of smoking and techniques to quit smoking. Nevertheless, he himself is a smoker and has no intention of giving it up.

Would we claim this smoking behaviour constitutes a failure of health literacy? Traditional definitions of health literacy would give an ambiguous response. His literacy includes all competences that "being literate" in health implies, but his choices belie his expertise.

Example 2 Karen goes to the gym 4-5 days every week for at least an hour performing aerobic exercises good for strengthening her heart as well as staying in shape. She is rigorous in her food intake, limiting sugar, animal fat, and caffeine. Karen appears to be showing great health literacy and empowerment. Yet, we discover that, far from thinking about her health, Karen does all this because her boyfriend Jason is the owner of the gym and she is often depressed as she struggles to "look the part" of Jason's girlfriend.

Would we define Karen's behaviour as a good application of health literacy? Clearly not. Her healthful behaviours are not oriented to the promotion of health and reflect anything but "health literate" motives and choices.

What our examples show is that, first and foremost, although there is a link between health literacy and behaviour, that link is neither necessary nor sufficient. What is needed to forge this link is the primacy of an existential goal of health enhancement. It is this goal that would motivate Andrew to quit smoking and provide a positive rationale to Karen's behaviour. The problem, of course, is that people have multiple goals, among which health is one, certainly not the only one, and in some cases not even the most important one. Thus, the behaviour of highly functionally literate people who do not act accordingly can be explained by the fact that for these people the pleasure of smoking or the importance of the maintenance of a relationship take priority over health.

On the other hand, prioritising the health-enhancement goal as part of the definition of health literacy would fail to consider the richness of the existential dimensions of the individual and ultimately deny the importance of freedom of choosing how to live one's own life. It might well be the case that specific life events lead people to change their goals, e.g. the occurrence of an illness might motivate a 
person who has so far enjoyed smoking to seriously think about stopping his habit. But this goal revision is rarely made a priori against the status quo; more often it is a function of the salience of health at specific moments of life. Moreover, it arises while reflecting on a complex set of individual and social factors that form a context in which the importance of health enhancement is either prioritized or diminished.

Provided that health enhancement is the goal, then, how does a person capitalize on his health literacy to advance this goal? This leads us to re-consider the nature of health literacy.

\section{Health literacy as phronesis}

Current conceptualisations of health literacy start from theoretical assumptions about the person as individual and as part of a community. This approach has identified a set of skills that supposedly constitute the domain of health literacy. While the skill-attainment view has beneficially enriched the notion of health literacy, it risks overlooking another central element of health literacy.

If health literacy is to be important to healthy choices and behaviour, it has to be internalized (Schulz and Nakamoto 2005); it has to be integral to the lived experience of the person. In our view, "critical" health literacy reflects the individual's capacity to contextualise health knowledge for his or her own good health, to decide on a certain action after a full appraisal of what that specific action means for them "in their own world". This critical reflection is an essential step for the application to concrete action of any health knowledge that would otherwise be "external" to the person and of any skill that would otherwise remain in its potentiality (e.g. I can be skilful in writing and never write).

What this critical reflection involves can be illustrated by exploring some messages left by patients affected by chronic low back pain on the online forum of a website. ONESELF was designed as part of a project for enhancing self-management of chronic low back pain (Schulz et al. 2007; Rubinelli et al. 2007); on this website patients and health professionals could interact either in a synchronous or asynchronous way.

- Patient B: "I have been suffering from back pain for about 3 years and I was diagnosed with a slipped disc in my lumbar vertebrae [...] could it depend on the way I sleep?"

- Patient C: "[...] what could be the cause of a burning sensation in the lower part of my back?"

- Patient D: "A few months ago I had pain 2 times in my sciatic nerve. The first time I took an anti-inflammatory and the pain passed after a bit, the second time I was more worried because at a certain point my leg gave in. I took another anti-inflammatory and again I was fine. Now it has been a few months and nothing like that has happened again. Could these be sporadic events that I don't have to worry about or do I need to get checked out?"

- Patient F: "Seeing the "gym" part of ONESELF I felt a bit guilty because I spend most of the day on my computer in the office. When I should go to the gym in reality I don't go. I would like to know if someone else has this problem and how they motivate themselves. I promise that I know that staying so sedimentary doesn't help."

In these queries, patients use the forum to gather information at a declarative (the knowledge of the "that") and procedural (the knowledge of the "how") level. Yet, we see that patients also attempt to contextualise this propositional knowledge; they ask health professionals for advice in order to interpret their experiences in terms of the professional's more generalized knowledge. In terms of health literacy, what we learn from the above messages is that this critical component essentially involves the ability to engage in an act of self-examination. The patient notes refer to physical or psychological experiences which they seek to explain or to act to overcome and they seek expert advice in order to do so. The patients, however, do not seek to become experts but rather to get an "overview" of aspects and limitations that, once made their own as personalized knowledge they as individuals need to address before engaging in health decisions and actions.

Such self-examination suggests a form of "practical wisdom" or phronesis. As portrayed in the original Aristotelian account found in the "Nicomachean Ethics" (Broadie and Rowe 2002; Bostock 2000; Irwin 1978), phronesis, in its broad sense, is the wisdom that the person applies when attempting to reach a goal. For Aristotle, this goal is "happiness" (the Greek "eudaimonia") that is "what is best for man of all things attainable in action". In our context the goal is health enhancement and the practical wisdom is the ability to identify the best route to this goal, which in turn entails the self-examination noted above in order to choose among the range of possible means to attain that goal. Health literacy as phronesis plays on this "all things considered" dimension: as an act of selfexamination it becomes the capacity of making health information relevant for action by recognizing those personal needs or limitations that can prevent its full appraisal and application in good health decisions. This critical selfexamination is the context in which health literacy relatedskills (as means to an end) come into play. In particular, phronesis requires that self-examination addresses at least 
four needs and limitations in order to enhance the patient's ability to capitalize on health literacy skills, namely:

a. understanding the limits of individual competence, which translates in the ability of asking for expert advice on issues about which the patient has limited expertise;

b. understanding subjective bias in the evaluation of health information, which translates in the ability to confront subjective evaluations with more objective data (e.g. grounded in medical knowledge and evidence);

c. understanding what information the patient has and what he does not know (particularly what he should know to make proper sense of a condition or a treatment), which translates into the ability to discover and fill eventual gaps in knowledge by asking appropriate questions;

d. understanding possible individual barriers to the application of appropriate advice, which translates into the ability to overcome these barriers by eventually asking for expert help.

To illustrate the criticality of this, consider the following example:

Example 3 Paul is overweight, recognizes that his health is threatened by obesity-related diseases, and decides to lose weight. He is knowledgeable of diet issues and has previously participated in several programmes for losing weight. His doctor recommends a rigorous diet and exercise programme, telling him there is no substitute for a healthy lifestyle. Instead, Paul finds on the Internet a "nutritional supplement" that promises weight loss regardless of diet. Paul purchases the rather expensive supplement and after 2 months of sedentary enjoyment of his usual high-calorie diet, Paul is embarrassed to find he has gained $2 \mathrm{~kg}$.

Paul has the functional literacy skills needed to lose weight and moreover, health enhancement is his goal. Where then is the problem? Paul fails to understand the limits of his competence, fails to address his subjective bias (the motivational barriers to maintaining a healthy lifestyle), fails to recognize his knowledge gaps (regarding the effectiveness of the supplement), and fails to address such gaps through appeal to an expert.

In other words, the concept of phronesis highlights a third essential level of health literacy represented by those subjective considerations that emerge from self-examination and that motivate a person to act in ways that promote good health. We refer to these subjective considerations as the "critical component" of health literacy. Nutbeam (2000) includes such considerations in his "critical health literacy". However, he presents them in light of a social and political dimension that is different from the individual one adopted in this paper. Health literacy is subjective in the sense that it entails the use by the individual of information and advice as relating to the self. It implies the "wisdom" of understanding what is important to a health decision so that one can apply the appropriate skills.

Health literacy does not, however, favour "subjectivism" in the form of falsification or freedom of re-interpretation of facts. Self-examination and the application of skills might lead one to decide not to follow specific treatment advice or to negotiate for changing it in a way that better suits one's life. However, if literacy is to lead to better health outcomes and physical well-being, the literate person cannot distort or ignore relevant facts; as Paul ignored his doctor's advice. If health literacy does not imply omniscience-and not even that complete information that in most, if not all, cases is not attainable-it requires acceptance of truth and the eventual correction of erroneous or inconsistent beliefs.

\section{Conclusion}

Our analysis suggests that the health-literate person occupies an admittedly ill-defined middle ground. We expect a literate person to be able to recognize the need to consult an expert, but not to become the expert. Moreover, neither theoretical knowledge nor skills alone have much power in guiding a "literate" decision. Instead, good health decisions depend particularly on two factors: focus on the goal of health-enhancement and a capacity for self-examination that then inspires appropriate use of skills. Goals are by definition not part of health literacy competence, but selfexamination is an essential component of health literacy as it is a process that helps the person whose goal is health to attain it. Self-examination connects health information external to the individual with her own worlds of knowledge, beliefs, and values, and prompts a recognition of potential failures that might and, indeed, often do obstruct the achievement of a goal. Recognizing the limits of one's own expertise and the ability to seek information from experts are central to avoiding these obstacles.

Understanding health literacy as phronesis ultimately corresponds to our idea of what "health empowerment" really means. It entails neither the pale shadow of the professional's expertise nor the relativist denial of its possibility. It is not merely challenging the "authority" of the professional. The value of engaging in self-reflection "informed" by explicit goals as well as a base of declarative and procedural knowledge is to allow the patient to be a patient; interacting with health professionals effectively (asking the right questions) so as to enhance their health and, in a real sense, taking ownership of it. For the health provider, health-literate patients, far from being a threat, 
are an asset; patients who can make clear their health concerns, not only in terms of disease or disability but also in terms of health as an integral element of life.

Acknowledgments We thank the National Research Programme NRP 53 'Musculoskeletal Health-Chronic Pain' of the Swiss National Science Foundation for the financial support of the study ONESELF (project 405340-104841/1), as well as the Lega Ticinese per la Lotta contro il Reumatismo, which has enabled its feasibility. We also thank Dr. Marta J. Wünsch for her inspiring comments on sections of this paper.

\section{References}

Abel T (2007) Cultural capital in health promotion. In: McQueen D, Kickbusch I, Potvin L et al (eds) Health and modernity. The role of theory in health promotion. Springer, New York, pp 43-73

Ad hoc committee on health literacy for the counsel of scientific affairs. American Medical Association (1999) Health literacy, Report of the Council of Scientific Affairs. JAMA 28:552-557

Andrus MR, Roth MT (2002) Health literacy: a review. Pharmacotherapy 22:282-302

Bostock D (2000) Aristotle's ethics. Oxford University Press, Oxford

Broadie S, Rowe CJ (2002) Aristotle: Nicomachean ethics. Translation, introduction and commentary. Oxford University Press, Oxford

Brown DR, Ludwig R, Buck G et al (2003) Health literacy: universal precautions needed. J Allied Health 33:150-155

Cutilli CC (2005) Health literacy-what you need to know. Orthop Nurs 24:227-231

Davis FD (1997) Phronesis, clinical reasoning, and Pellegrino's philosophy of medicine. Theor Med 18:173-195

DeBuono B (2004) Health literacy: a hidden and critical challenge to effective health care. AHIP Cover 45:38-40

Dubow J (2004) Adequate literacy and health literacy: prerequisites for informed health care decision making. AARP Public Policy Inst 2004:1-11

Irwin TH (1978) First principles in Aristotle's ethics. Midwest Stud Philos 72:567-578

Kickbusch I, Ratzan SC (2001) Health literacy: making a difference in the USA. J Health Commun 6:87-88
Kickbusch I, Maag D, Saan H (2005) Enabling healthy choices in modern health societies. European Health Forum Gastein, 6th October, Bad Gastein

Levin-Zamir D, Peterburg Y (2001) Health literacy in health systems: perspectives on patient self-management in Israel. Health Promot Int 16:289-297

Maag D (2005) Health literacy. Compendium of prior research. In: Schulz PJ, Nakamoto K (eds) SComS. Special Issue on Health Literacy 5:11-27

Macnaughton RJ (1998) Evidence and clinical judgment. J Eval Clin Pract 4:89-92

McCray AT (2005) Promoting health literacy. JAMIA 12:152-163

Nutbeam D (2000) Health literacy as a public health goal: a challenge for contemporary health education and communication strategies into the 21st century. Health Promot Int 15:259-267

Nutbeam D, Kickbusch I (2000) Advancing health literacy: a global challenge for the 21st century. Health Promot Int 15:183-184 (editorial)

Parker R (2000) Health literacy: a challenge for American patients and their health care providers. Health Promot Int 15:277-283

Parker R, Ratzan S, Lurie N (2003) Health literacy: a policy challenge for advancing high quality care. Health Aff 22:147-153

Ratzan SC (2001) Health literacy: communication for the public good. Health Promot Int 16:207-214

Rubinelli S, Schulz PJ, Vago F (2007) Designing and evaluating online communities for promoting self-management of chronic low back pain. IJWBC 4:80-97

Schloman B (2004) Health literacy: a key ingredient for managing personal health. Online J Issues Nurs 9:14-23

Schulz PJ, Nakamoto K (2005) Emerging themes in health literacy. Special Issue on Health Literacy 5:1-10 (editorial SComS)

Schulz PJ, Rubinelli S, Hartung W (2007) An internet based approach to enhance self-management of chronic low back pain in the Italian-speaking population of Switzerland: results from a pilot study. Int J Public Health 52:286-294

Tones K (2002) Health literacy: new wine in old bottles? Health Educ Res 17:287-290

Wang R (2000) Critical health literacy: a case study from China in schistosomiasis control. Health Promot Int 15:269-274

Williams MV, Parker RM, Baker DW et al (1995) Inadequate functional health literacy among patients at two public hospitals. JAMA 274:1677-1682

World Health Organization (1998) Health promotion glossary. Verlag für Gesundheitsförderung, Gamburg 